\title{
Microplastics in Mollusks: Research Progress, Current Contamination Status, Analysis Approaches, and Future Perspectives
}

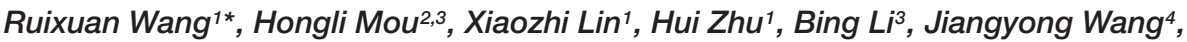 \\ Muhammad Junaid ${ }^{5}$ and Jun Wang ${ }^{5 *}$
}

'School of Life Sciences and Food Engineering, Hanshan Normal University, Chaozhou, China, ${ }^{2}$ School of Marine Science, Shanghai Ocean University, Shanghai, China, ${ }^{3}$ South China Sea Fisheries Research Institute, Guangzhou, China, ${ }^{4}$ South China Sea Fisheries Research Institute, Chinese Academy of Fishery Sciences, Huizhou University, Huizhou, China, ${ }^{5}$ College of Marine Sciences, South China Agricultural University, Guangzhou, China

OPEN ACCESS

Edited by:

Satya Panigrahi, Indira Gandhi Centre for Atomic

Research (IGCAR), India

Reviewed by:

1. Gede Hendrawan,

Udayana University, Indonesia

Tadele Assefa Aragaw,

Bahir Dar University, Ethiopia

${ }^{*}$ Correspondence:

Ruixuan Wang

wangruixuan@scsfri.ac.cn

Jun Wang

wangjun2016@scau.edu.cn

Specialty section:

This article was submitted to Marine Pollution,

a section of the journal

Frontiers in Marine Science

Received: 17 August 2021 Accepted: 20 October 2021 Published: 18 November 2021

Citation:

Wang $R$, Mou $H$, Lin X, Zhu H, $L i B$, Wang J, Junaid $M$ and Wang J (2021) Microplastics in Mollusks.

Research Progress, Current Contamination Status, Analysis

Approaches, and Future

Perspectives.

Front. Mar. Sci. 8:759919. doi: 10.3389/fmars.2021.759919
Plastic fragments $<5 \mathrm{~mm}$, known as microplastics (MPs), are ubiquitously present in the marine environment. Research on MPs pollution has gradually shifted from field investigations to laboratory studies. With the rapid growth of plastic consumption and the prevalence of aquaculture products, studies on marine MPs have focused on key marine species, such as mollusks. This review summarizes the recent knowledge including 77 important relevant literatures (from 2010 to 2021) on MPs contamination in mollusks with the objectives of (1) elucidating the current status of MPs pollution levels in mollusks, (2) highlighting the main methods and techniques for separation, extraction, and identification of MPs in soft tissues of bivalves and (3) presenting the current research progress and future directions. The review visually presents some of the important results in graphic form, which shows that the most common polymer plastics in bivalves are polypropylene, polystyrene, and polyethylene, and the shapes were mainly fiber and threadiness, mollusks are more likely to feed smaller MPs, most of the MPs in bivalves are less than $500 \mu \mathrm{m}$, and the abundance of MPs in seawater and the abundance of MPs in mollusks have a positive relationship, etc. This review will provide a comprehensive reference for studies of microplastics in marine organisms and the ecological pollution, and also has scientific guiding significance in the research method.

Keywords: microplastics, mollusks, bivalves, methods, contamination status

\section{INTRODUCTION}

Microplastics (MPs) refer to miniature plastic particles having a size of less than $5 \mathrm{~mm}$, which form after large plastic waste enters the aquatic environment and breaks down due to the influence of photodegradation, physical degradation, and biodegradation (Browne et al., 2008; Moore, 2008; Cole et al., 2011). Recent studies have further defined plastic particles smaller than $0.1 \mu \mathrm{m}$ as "nanoplastics" (Alimi et al., 2018). Plastic waste accounts for $80-85 \%$ of the total marine waste (Auta et al., 2017), and it is still increasing. Plastics are widely used in the commercial, industrial, 
and pharmaceutical industries as they are lightweight, durable, inert, and resistant to corrosion. By 2016, global annual plastic production had surpassed 335 million tons, with disposable packagings such as plastic bags and soft drink bottles accounting for the majority of this total (Silva et al., 2018). It has been estimated that 4.8-12.7 million tons of MPs are released into the oceans every year, of which about 5 trillion MPs float on the surface (Eriksen et al., 2014). It has been reported that freshwater environmental input accounts for $70-80 \%$ of total MPs in the marine environment (Desforges et al., 2014). MPs inland and the atmosphere will eventually reach the ocean; therefore, oceans serve as the sink for all kinds of plastics including MPs (Xia et al., 2020). Increased MPs pollution has also resulted from the increased use of plastic products and insufficient management measures. In aquaculture systems, especially in industrially developed and densely populated areas, MPs pollution is more prominent. Household supplies, detergents, cosmetics, or drug carriers are the main sources of MPs (Fendall and Sewell, 2009; Patel et al., 2009). Synthetic fibers released from textiles are the main type of MPs in coastal sediments (Browne et al., 2011; Galvão et al., 2020). Therefore, MPs can enter aquaculture systems either directly or indirectly, negatively impacting the industry.

Mollusks are rich in nutrition, high economic value, and easy to breed. They are a highly regarded aquaculture resource, especially bivalves, which are typical filter feeders, constantly filtering out microbes and organic matter from the surrounding water (Xu et al., 2017). As a result, it is critical to monitor MPs in mollusks. MPs have been recorded in commercial mollusks, especially in Mytilus edulis (Graham et al., 2019). Based on the estimation of MPs found in two kinds of mussels sold on the European market, the annual dietary exposure of European mollusk consumers could reach 11,000 MPs (Van Cauwenberghe and Janssen, 2014). Bivalves are widely distributed, so some of them are considered as biological indicators for monitoring MP pollution in coastal areas, such as M. edulis, etc. (Beyer et al., 2017).

Great progress has been made in the study of MPs contamination in bivalves. However, there are still many challenges in quantifying, identifying, and characterizing MPs accurately. The increasing number of studies and the variability of methods used for particle separation, quantification, and identification have led to false comparability of data and conclusion. Since the study of MPs in bivalves is becoming more and more important worldwide, it is essential to analyze and compare the diversity and variability of analytical methods for the separation, quantification, and characterization of MPs in bivalves reported in the literature. However, little work has been done on this to date. Therefore, this article collates the recent knowledge including 77 relevant literatures (from 2010 to 2021) on MPs contamination in mollusks with the objectives of (1) elucidating the current status of MPs pollution levels in mollusks, (2) highlighting the main methods and techniques for separation, extraction, and identification of MPs in soft tissues of bivalves and (3) presenting the current research progress and future directions. This review will provide a comprehensive reference for studies of microplastics in marine organisms and the ecological pollution, and also has scientific guiding significance in the research method.

\section{ABUNDANCE AND BIOACCUMULATION OF MICROPLASTICS IN MOLLUSKS}

\section{Compositional Profiles Microplastics in Mollusks}

Microplastics ingested by mollusks differ in size, shape, color, and polymers. As the characteristics of MPs will affect their utilization rate by mollusks, we collected and analyzed information about the compositions of ingested MPs (Supplementary Table 1 and Figure 1). According to their morphological characteristics, MPs are usually classified as fiber/line, fragments, films, pellets/balls, and foams. Fibers, fragments, films, and pellets, dominate in many freshwater and coastal areas, with fibers accounting for more than 50\% (Figure 1A). It is not clear whether the fibers have a higher bioavailability or if they are the most abundant MPs in the sampling areas. MP's colors in mollusks are mainly blue, white, and black (Figure 1B). Plastics are synthetic polymers made from a variety of compounds with different properties. The types and content of MPs in bivalves are closely related to MPs in seawater. The main plastic components of MPs in seawater are polypropylene (PP), polyethylene (PE), polyvinyl chloride (PVC), polystyrene (PS), and polyethylene terephthalate (PET) (Andrady, 2011), which are also the most widely used plastics and account for about $90 \%$ of global plastic products (Andrady and Neal, 2009). The most common polymer plastics in bivalves are PP, PS, and PE (Figure 1C). The particle size of MPs directly affects their migration in water and whether they can be absorbed by organisms (Cole et al., 2020), which is closely related to biological safety. Mollusks are more likely to feed smaller MPs. Most of the MPs in bivalves are less than $500 \mu \mathrm{m}$ (Figure 1D). The smaller the microplastics, the greater the damage to the mollusks (Wu et al., 2019; Bringer et al., 2020a). In addition, particle dosage (Song et al., 2020), charge (Junaid and Wang, 2021), exposure time (Song et al., 2020), type and additives also determine the effect (Banerjee and Shelver, 2021).

The abundance of MPs in seawater and the abundance of MPs in mollusks have a positive relationship. The main sources of MPs in marine aquaculture farms are the aging, water flow conditions, and disintegration of fishery equipment. Wind and upwelling also affect the distribution of plastic waste (David et al., 2009; Van Emmerik et al., 2019). MPs abundance in surface seawater is also positively correlated with river runoff, watershed area, population, and urbanization rate (Tang et al., 2018). MPs can largely disseminate in the environment, and the distribution of MPs varies among different spatiotemporal settings. When the density of MPs is greater than that of seawater, such as PS (1.04$\left.1.1 \mathrm{~g} \mathrm{~cm}^{-3}\right)$ and PVC (1.16-1.58 $\left.\mathrm{g} \mathrm{cm}^{-3}\right)$, they will sink and eventually accumulate in marine sediments. When the density of MPs is less than that of seawater, such as low-density PE (0.89-0.93 $\left.\mathrm{g} \mathrm{cm}^{-3}\right)$, high-density PE $\left(0.94-0.98 \mathrm{~g} \mathrm{~cm}^{-3}\right)$, PP (0.83-0.92 $\left.\mathrm{g} \mathrm{cm}^{-3}\right)$, plastic particles float on the sea surface, 


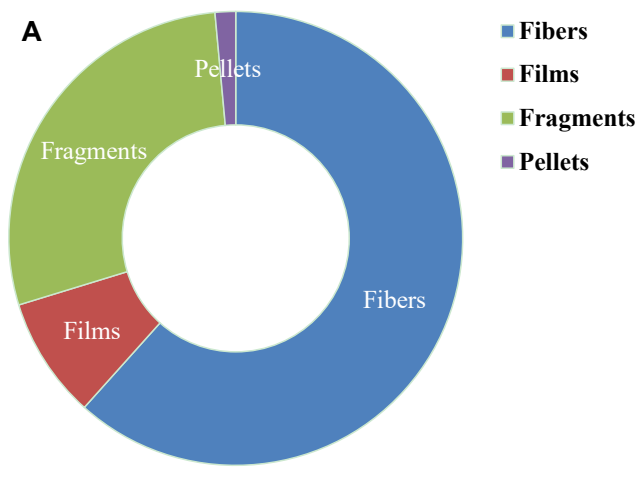

MPs shape distribution

C

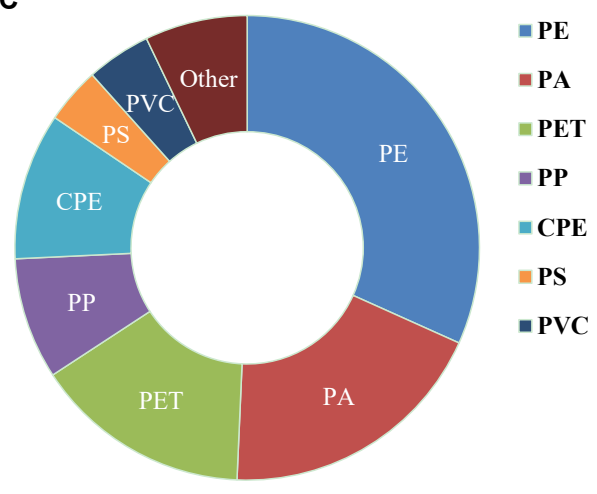

MPs polymer types

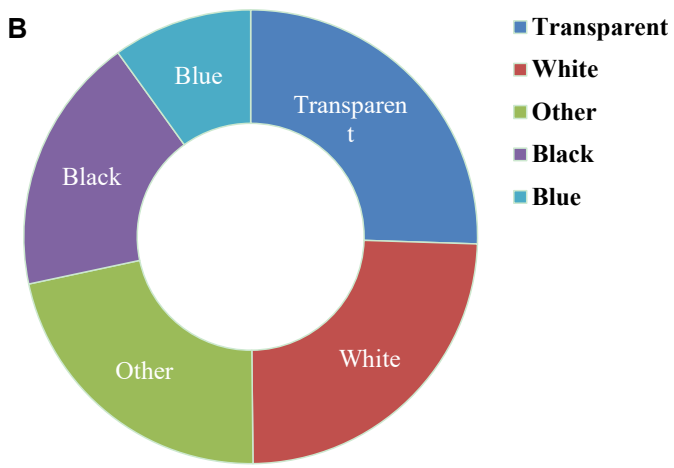

MPs color distribution

D

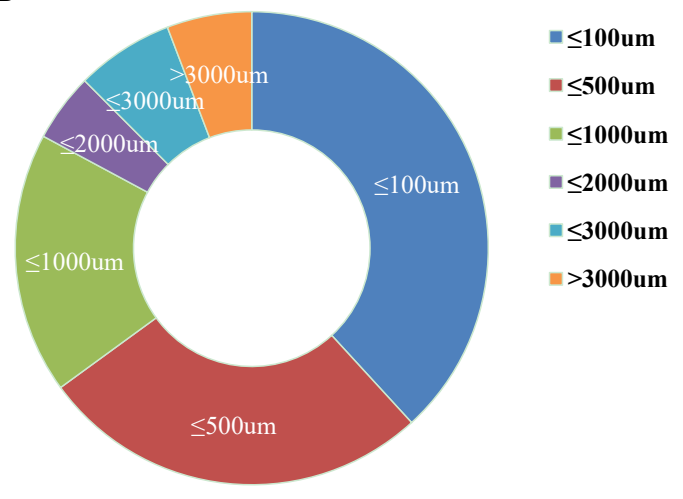

MPs size in molluscs

FIGURE 1 | Composition profiles (shape, color, polymer type, and size) of microplastics (MPs) in mollusks. (A) Description of shape is contained in the first panel; (B) Description of color is contained in the second panel; (C) Description of polymer type is contained in the Third panel; (D) Description of size is contained in the fourth panel.

but they are affected by migrating to the coastline under the influence of waves and tides, or sink into marine sediments under the influence of marine organisms (Suaria and Aliani, 2014; Junaid and Wang, 2021). Interestingly, MPs' intake amount and type differ between field and laboratory observations $(\mathrm{Qu}$ et al., 2018), while the units used in the report of MPs' abundance are inconsistent. Such discrepancies in results create difficulties to summarize the geographical distribution patterns and further comparison of MPs' pollution levels.

\section{Bioaccumulation of Microplastics at the Tissue Level}

Feeding is the main pathway by which MPs enter mollusks. When mollusks are exposed to MPs in the water, they remove most of the MPs through a process known as purification/filtration. The remaining MPs are mainly accumulated in the digestive glands and gills of mussels (Green et al., 2019). Then the MPs will enter mollusks through the surface microvilli or the ciliary movement of the gill and endocytosis (Pedersen et al., 2020). Some of the small plastic particles are swallowed by the cells in the entrails, move through the epithelial cells, and are transferred to the hemolymph (Scanes et al., 2019). Most MPs are excreted in vivo as pseudo feces. Some MPs entering the gills may also be identified by mollusks and directly discharged from the body. However, it has been reported that MPs can permeate the foot, mantle, and shells of mollusks through adherence (Kolandhasamy et al., 2018; Zhu et al., 2020). Different pollutants gather at different locations. In Pacific oysters (Crassostrea gigas), it was found that cytokinin tended to accumulate in gill, mantle, and muscle tissue, while polyester tended to accumulate in the entrails (Zhu et al., 2020). Therefore, the digestive tract of mussels cannot be regarded as the only sink for MPs.

\section{RESEARCH PROGRESS IN MICROPLASTICS MEDIATED CONTAMINATION IN MOLLUSKS}

Under certain environmental conditions, the biological uptake of MPs may be selective. It is generally believed that, compared with predatory species, mollusks absorb MPs more easily due to their filter-feeding behavior (Wesch et al., 2016) and efficient 


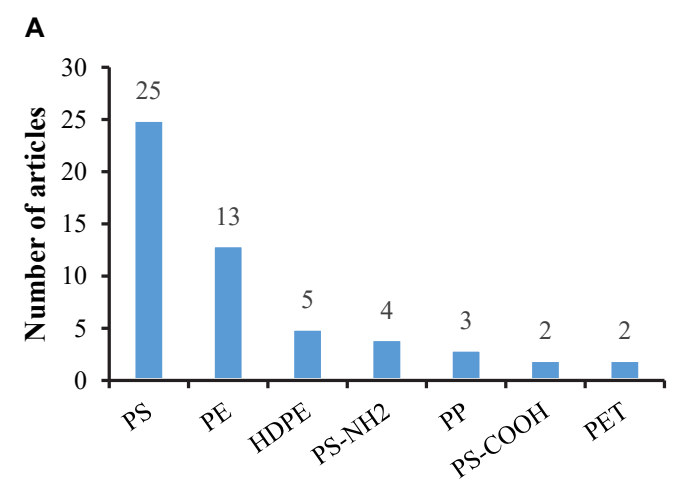

MPs polymer type

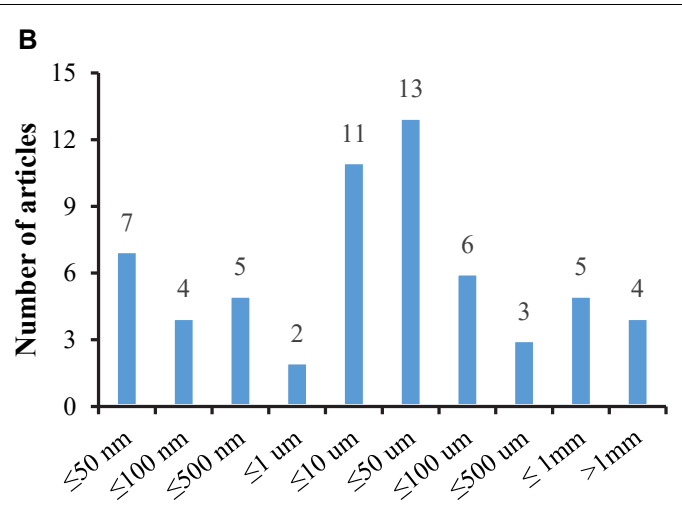

MPs size

FIGURE 2 | The number of articles that have tested MPs in bivalves according to the polymer type and size: (A) Description of MPs polymer type is contained in the first panel; (B) Description of MPs size is contained in the second panel.

water purification capacity (Xu et al., 2017). Available studies have mainly focused on MPs' polymer type, size, exposure time, attached pollutants, and test-related indicators to reflect the impact of MPs on mollusks. Due to the small size of MPs, they are ingested by mollusks along with their food (e.g., microalgae) in the environment (Fernández and Albentosa, 2019a). Our data analysis showed that research has mainly focused on small-sized plastic particles with large yields (Figures 2A,B).

Microplastics can be transferred to the hemolymph, muscle, and other tissues or organs through phagocytosis (Scanes et al., 2019). Many of them are identified by bivalves as foreign elements then are removed (Birnstiel et al., 2019; Graham et al., 2019). It is suggested that MPs that reach the digestive tract are packaged into fecal particles and eliminated, but some of them will remain in the digestive tract (Fernández and Albentosa, 2019b), which are likely to affect the gut microbiota and damage internal organs (for example, hepatopancreas). Disorders of the gut microbiota usually lead to colitis and other abnormal behaviors (Glenny et al., 2017), and it has been confirmed that species exposed to microplastics for a long time suffer from gut biological disorders and inflammation (Jin et al., 2018; Fackelmann and Sommer, 2019), and the intestine may pass through selective removal and/or enrichment of certain bacterial taxa affects the related microbial community, thereby forming an obvious intestinal biofilm community on the particles (Kesy et al., 2016). Mollusks lack enzymes and have limited enzymatic pathways to decompose plastic (Wright et al., 2013), which will lead to long-term retention of MPs (Corami et al., 2020), affecting their reproductive, immune, and neurological systems (Prata et al., 2020). The absorption of MPs by clams varies with polymer type, concentration, color, and size (Li et al., 2019a), with particle size being a key factor (Cole et al., 2020). At the same time, it can be seen from Figure 3 that the main focus is on short-term acute exposure experiments, while microplastics can exist for hundreds of years. Studies have found that the absorption (intake or adhesion) of MPs by mussels was positively correlated with the exposure time. It is implied that the amounts of MPs in mussels increase with the growth of mussels (Berglund et al., 2019).

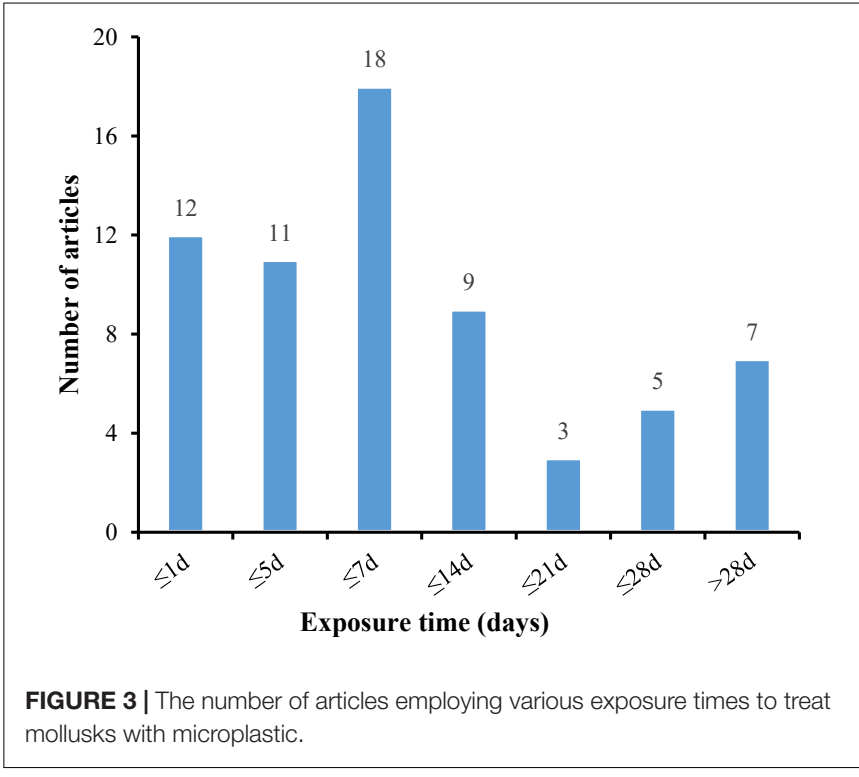

Therefore, the focus of subsequent research will be the long-term harm of microplastics to organisms.

To understand the impact of MPs on mollusks under environmentally relevant conditions, some studies added anthropogenic pollutants and bacteria to their exposure solutions (Figure 4). Microplastics serve as carriers for multiple environmental pollutants in the aquatic environment. For instance, environmental pollutants such as metals and antibiotics adsorb and accumulate on the surface of MPs and may aggravate the hazards of those pollutants as well as those of MPs. Studies have reported the multifaceted mixture effects of MPs and other chemicals including biological oxidative stress, abnormal energy supply, and cell death in mollusks (Antunes et al., 2013; Canesi et al., 2015). Moreover, MPs have a large surface area that can carry microorganisms (Frère et al., 2018; Bowley et al., 2021), including bacterial pathogens (such as Vibrio parahaemolyticus, V. vulnificus etc.), which also pose a threat to human health. It has 


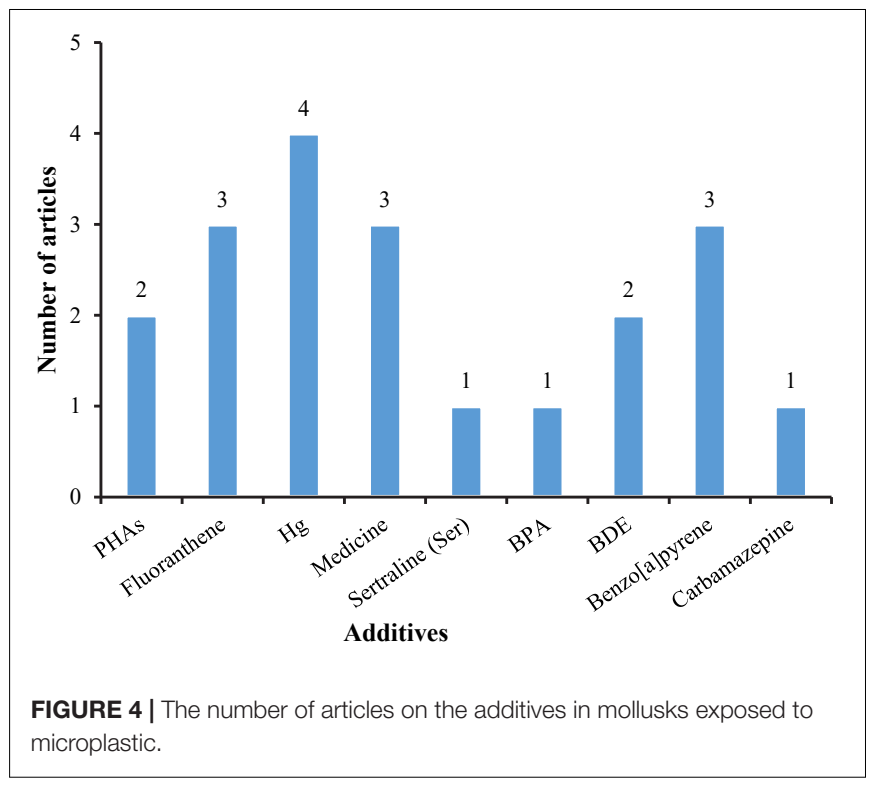

been confirmed that when the mussels (M. edulis) contaminated with PS-MPs were fed to crabs (Carcinus maenas), then the PS-MPs were found in the stomach, hepatopancreas, ovaries, gills, and hemolymph of crabs, with the highest content in the hemolymph (Farrell and Nelson, 2013). This indicated that MPs could be accumulated in biological tissues and be transferred along with the food web (Fernández and Albentosa, 2019b).

Plastic additives are also environmental pollutants, which are chemicals added to improve the processing, physical, and chemical properties of plastic substrates. They are easily leached from plastic products and can be detected in both the aquatic environment and organisms (Huppertsberg and Knepper, 2018; Llorca et al., 2021). Plastic additives such as the flame retardant hexabromocyclododecane, polycyclic aromatic hydrocarbons and polybrominated diphenyl ethers were detected in plastic fragments floating in the ocean and expanded polystyrene buoys in the breeding area (Rani et al., 2017; Chen et al., 2018). The leachate in the disposable polyethylene plastic bag can significantly affect the growth of the clam (Meretrix meretrix) (Ke et al., 2019). Plastic additives also exhibit negative effects on mollusks, including oxidative stress, cytotoxicity, neurotoxicity, reproductive toxicity, growth and development toxicity, and disrupting their endocrine system (Zimmermann et al., 2019; Wang et al., 2020). Besides, MPs are small and light-weight particles, which make them easy to be transported to remote places through water flow or water currents.

Figures 5, 6 show that most of the previous studies, through analyzing changes in antioxidant defense system entities, such as malondialdehyde (MDA), superoxide dismutase (SOD), and reactive oxygen species (ROS), etc., found that MPs exposure can affect the immune system in mollusks. Several studies also used histopathological analyses to observe the tissue damage mediated by MPs in mollusks. Further, malformations of the nervous system, changes in growth and development (GonzálezFernández et al., 2018), physiological behavior alteration, and adverse effects on the reproduction and heredity of mollusks were also reported as toxic effects, amongst others (Bringer et al., 2020b).

\section{METHODS FOR ISOLATION AND CHARACTERIZATION OF MICROPLASTICS IN MOLLUSKS}

\section{Dissolution}

The initial stage in MPs separation is dissolution, which is the process of decreasing the organic content of mollusks and collecting MPs. The amount of time it will take the researcher to extract the MPs from the samples, as well as the potential dangers connected with the reagents, are critical concerns. The impact of the dissolution process on the color and shape of MPs is critical, as these characteristics provide information about the MPs' origins and the presence of additives. Chemical and enzymatic dissolution is the most widely utilized techniques nowadays.

Chemical dissolution mainly uses acid, alkali, and $\mathrm{H}_{2} \mathrm{O}_{2}$ to dissolve tissues. The acid decomposes organic matter such as proteins, carbohydrates, and oil, and also dissolves fragments such as bones and shells. Although strong acids have good dissolution effects, they will also destroy the structure of MPs. Polyamide and polyurethane are completely degraded during the $\mathrm{HNO}_{3}$ dissolution method, and PET structure is destroyed and fused (Claessens et al., 2013). Alkalis can hydrolyze chemical bonds and denature proteins. One of the most commonly used strong alkali reagents is $10 \% \mathrm{KOH}$. It is typically incubated at $60^{\circ} \mathrm{C}$ and $30 \mathrm{rpm}$ in $10 \% \mathrm{KOH}$ at 1:5 (M: V) (Zhang et al., 2020a). This method has less reagent dosage and a short reaction time can quickly and effectively dissolve a large number of samples and has little effect on most polymer particles (Ding et al., 2018). It cannot dissolve cellulose, chitin, and silica, and can cause degradation of polymers such as polycarbonate, PA, and PET (Hurley et al., 2018). Therefore, $30 \% \mathrm{H}_{2} \mathrm{O}_{2}$ is often used for the dissolution of organisms with chitin exoskeletons and organisms with high oil content in the organs (such as gonads, digestive tract, etc.). The dissolution temperature is generally $65^{\circ} \mathrm{C}, 200 \mathrm{~mL} 30 \% \mathrm{H}_{2} \mathrm{O}_{2}$ is used to dissolve $5 \mathrm{~g}$ tissue ( $\mathrm{Li}$ et al., 2019b). Although $\mathrm{H}_{2} \mathrm{O}_{2}$ can effectively dissolve biological tissues, a large volume of bubbles is produced during the dissolution process, which can easily cause the loss of MPs. It's worth noting that the oxidation of $\mathrm{H}_{2} \mathrm{O}_{2}$ will cause a variety of polymers to fade, and will slightly degrade $\mathrm{PP}$ and $\mathrm{PE}$.

A single chemical agent solution could not completely dissolve the tissue, often leaving undissolved residues at the bottom of the beaker. The mixture of $\mathrm{H}_{2} \mathrm{O}_{2}$ and acid is more effective, but $10 \%$ $\mathrm{KOH}$ is the most effective for the dissolution of biological tissues without affecting MPs, with a recovery rate of over 97\% (Liu et al., 2020). The same conclusion was also reached by comparing $\mathrm{H}_{2} \mathrm{O}_{2}$, proteinase $\mathrm{K}$, trypsin, and $\mathrm{KOH}$ to dissolve bivalve tissues, using the following indicators: filterability, dissolution efficiency, and recyclability of MPs. The MPs in the digestive system of bivalves can also be extracted with $\mathrm{KOH}$ (Ding et al., 2018). KOH can be used with spectroscopic analysis to detect MPs only several microns in size of bivalve tissues (Thiele et al., 2019). 


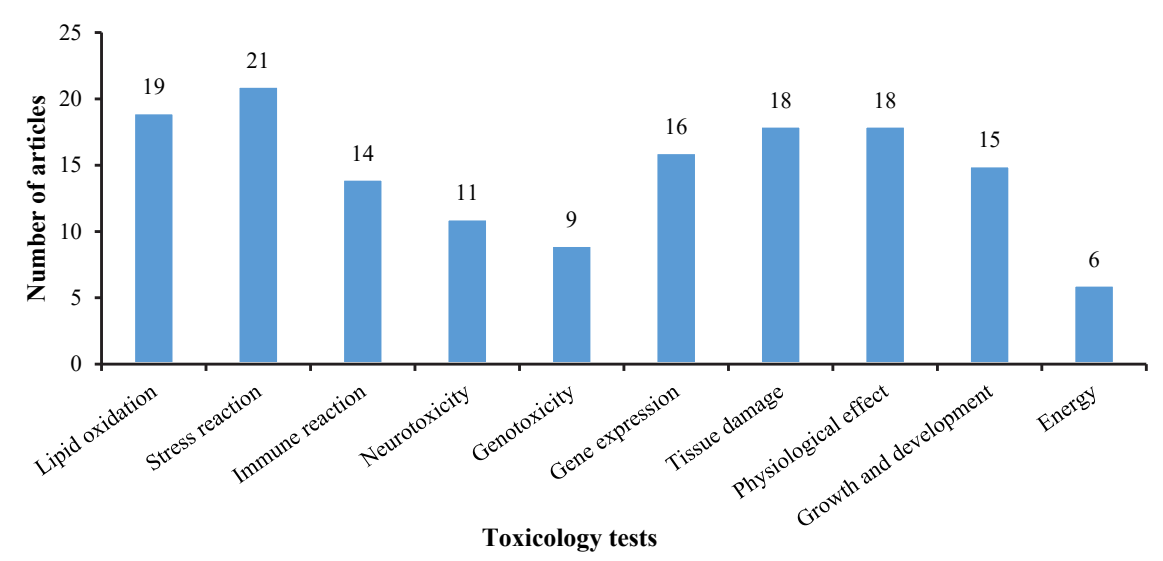

FIGURE 5 | The number of articles on the toxicological responses in mollusks exposed to microplastic.

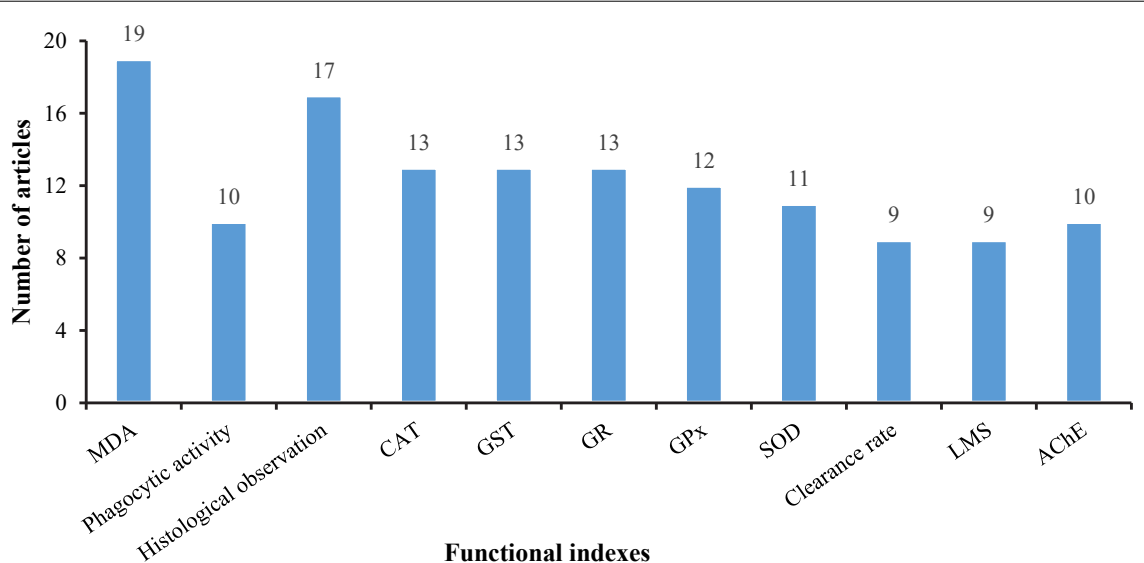

FIGURE 6 | The number of articles on functional responses in mollusks exposed to microplastics.

Enzymatic dissolution of biological tissues works by hydrolyzing proteins to obtain MPs in biological tissues. The enzymes used in this process are relatively mild, and the most commonly used enzymes are pancreatin (Von Friesen et al., 2019), lipase, amylase, and protease (Catarino et al., 2017). The cost of enzyme treatment is relatively high and the dissolution efficiency is relatively low, and it is thus only suitable for processing a small number of samples. In sum, for large quantities of samples, $10 \% \mathrm{KOH}$ and $30 \% \mathrm{H}_{2} \mathrm{O}_{2}$ are recommended as the most feasible dissolution methods for studying MPs in mollusks.

\section{Separation and Extraction}

When organic impurities are completely dissolved in mollusks samples, MPs are usually collected by density separation. The density separation approach uses density difference between MPs particles and environmental impurities for separation. For example, the density of MPs such as PE and PP produced by general industry is less than the density of water $\left(1 \mathrm{~g} \mathrm{~cm}^{-3}\right)$, they will float on the surface of the water, and impurities will settle to the bottom of the water. Studies have used
TABLE 1 | Density and advantages and disadvantages of flotation liquid.

\begin{tabular}{|c|c|c|c|}
\hline Flotation fluid & $\begin{array}{l}\text { Density } \\
\mathrm{g} \mathrm{cm}^{-3}\end{array}$ & Advantage & Disadvantage \\
\hline Alcohol & 0.8 & Non-toxic & Unable to float MPs \\
\hline Ultra-pure water & 1.0 & Non-toxic & $\begin{array}{c}\text { Unable to recover most } \\
\text { MPs }\end{array}$ \\
\hline $\mathrm{Nal}$ & 1.8 & Efficient & Toxic \\
\hline $\mathrm{ZnCl}_{2}$ & 1.8 & Efficient & High surface tension, Toxic \\
\hline $\mathrm{NaCl}$ & 1.12 & Non-toxic & $\begin{array}{l}\text { Unable to recycle } \\
\text { high-density plastic }\end{array}$ \\
\hline $\mathrm{NaH}_{2} \mathrm{PO}_{4}$ & 1.4 & $\begin{array}{l}\text { Non-toxic, } \\
\text { Efficient }\end{array}$ & $\begin{array}{l}\text { Unable to recycle } \\
\text { high-density MPs }\end{array}$ \\
\hline
\end{tabular}

The concentrations range of microplastics (MPS) is $0.8-1.8 \mathrm{~g} \mathrm{~cm}^{-3}$.

alcohol $\left(0.8 \mathrm{~g} \mathrm{~cm}^{-3}\right)$, ultrapure water $\left(1.0 \mathrm{~g} \mathrm{~cm}^{-3}\right), \mathrm{NaCl}$ (1.12 $\left.\mathrm{g} \mathrm{cm}^{-3}\right)$, $\mathrm{NaI}\left(1.8 \mathrm{~g} \mathrm{~cm}^{-3}\right)$, and $\mathrm{ZnCl}_{2}\left(1.8 \mathrm{~g} \mathrm{~cm}^{-3}\right)$ as flotation solutions to measure MPs with a density range of $0.8-$ $1.8 \mathrm{~g} \mathrm{~cm}^{-3}$. Alcohol and ultrapure water have a low density, it is impossible to collect plastic. $\mathrm{NaI}$ and $\mathrm{ZnCl}_{2}$ are harmful to the environment. In addition, the $\mathrm{ZnCl}_{2}$ solution has high surface 
TABLE 2 | Comparison analysis on the major methods for identifying MPs.

\begin{tabular}{|c|c|c|c|c|}
\hline $\begin{array}{l}\text { Identification } \\
\text { methods }\end{array}$ & Principle & Advantage & Disadvantage & References \\
\hline Microscope & Principles of optics & Simplicity of operation, Intuitive & $\begin{array}{l}\text { low resolution, Low accuracy, Uncertain } \\
\text { chemical composition of MPs }\end{array}$ & $\begin{array}{l}\text { Gniadek and } \\
\text { Dąbrowska, } 2019\end{array}$ \\
\hline SEM & $\begin{array}{l}\text { The electrons in the focused electron } \\
\text { beam interact with atoms in the sample }\end{array}$ & $\begin{array}{l}\text { High-resolution, high-resolution image, } \\
\text { three-dimensional image, and } \\
\text { non-destructive }\end{array}$ & $\begin{array}{l}\text { Disturbed by water, complex } \\
\text { pre-processing, required }(0.5-1.5 \mathrm{kV}) \text {, } \\
\text { and low currents }\end{array}$ & $\begin{array}{l}\text { Gniadek and } \\
\text { Dąbrowska, } 2019\end{array}$ \\
\hline Raman spectra & $\begin{array}{l}\text { When monochromatic light irradiates } \\
\text { the sample, the molecules (or atoms) } \\
\text { cause Stokes to scatter the incident } \\
\text { light, and the polarizability of the } \\
\text { molecule changes }\end{array}$ & $\begin{array}{l}\text { Rich information, simple sample } \\
\text { preparation, high-resolution ( } 1 \mu \mathrm{m}) \text {, and } \\
\text { non-destructive }\end{array}$ & $\begin{array}{l}\text { Affected by fluorescence, The signal is } \\
\text { susceptible to changes in a } \\
\text { measurement parameter }\end{array}$ & Xu et al., 2019 \\
\hline FTIR & $\begin{array}{l}\text { When infrared light irradiates a } \\
\text { molecule, its chemical bond or } \\
\text { functional group undergoes vibrational } \\
\text { absorption, resulting in a change in the } \\
\text { dipole moment }\end{array}$ & $\begin{array}{l}\text { Rich information, high-resolution } \\
(10 \mu \mathrm{m}), \text { fast scanning speed, high } \\
\text { sensitivity, and non-destructive }\end{array}$ & $\begin{array}{l}\text { Disturbed by water, Fourier transform } \\
\text { infrared spectra obtained in different } \\
\text { modes are different, Effect of Chemical } \\
\text { Degradation on Vibrational Spectral } \\
\text { Band of Plastics }\end{array}$ & Xu et al., 2019 \\
\hline DSC & $\begin{array}{l}\text { The changing heat capacities during } \\
\text { the solid-liquid phase transition of a } \\
\text { polymer }\end{array}$ & Simplicity of operation & $\begin{array}{l}\text { required to identify polymer types, large } \\
\text { particles can cause interferences, } \\
\text { affected by production parameters, } \\
\text { Damaged samples }\end{array}$ & $\begin{array}{l}\text { Huppertsberg and } \\
\text { Knepper, } 2018\end{array}$ \\
\hline TGA & $\begin{array}{l}\text { Measure the relationship between } \\
\text { sample quality and temperature change } \\
\text { under program temperature control }\end{array}$ & $\begin{array}{l}\text { High accuracy, simplicity of operation, } \\
\text { and measuring quickly }\end{array}$ & $\begin{array}{l}\text { Affected by experimental conditions, } \\
\text { damaged samples }\end{array}$ & Xu et al., 2019 \\
\hline GC-MS & $\begin{array}{l}\text { GC separates mixed compounds; MS } \\
\text { identifies molecular mass }\end{array}$ & $\begin{array}{l}\text { Accurate identification of different } \\
\text { polymer types, information on } \\
\text { potentially toxic organic plastic } \\
\text { additives }\end{array}$ & $\begin{array}{l}\text { Cannot provide information on the } \\
\text { quantity, type, and shape of plastics, } \\
\text { Time consuming, rather for large debris } \\
\text { (manually handled by tweezers), } \\
\text { Damaged samples }\end{array}$ & Fries et al., 2013 \\
\hline
\end{tabular}

SEM, scanning electron microscope; FTIR, Fourier transform infrared spectroscopy; DSC, differential scanning calorimetry; TGA, thermogravimetric analyzer; GC-MS, pyrolysis gas chromatography-mass spectrometry.

tension (Li et al., 2018). When it is hot without using flotation solution, as the flotation fluid cannot suspend all the MPs, but the undissolved grease in the digestion fluid can easily condense and block the filter holes, some researchers directly filter the digestion solution. Thus, $\mathrm{NaCl}$ has become the main flotation agent used in the laboratory because of its non-toxicity and effectiveness. However, $\mathrm{NaCl}$ is limited by density and cannot recycle higherdensity plastics. The research found that $\mathrm{NaH}_{2} \mathrm{PO}_{4}$ solution can overcome this shortcoming. As the temperature increases, its solution density also increases. The density for saturated $\mathrm{NaH}_{2} \mathrm{PO}_{4}$ solution measured at 20,30 , and $40^{\circ} \mathrm{C}$ is $1.4,1.46$, and $1.51 \mathrm{~g} \mathrm{~cm}^{-3}$, respectively (Zhang et al., 2020b). $\mathrm{NaH}_{2} \mathrm{PO}_{4}$ exhibits high extraction efficiency and non-toxic nature, indicating the potential application of this solution for extraction is broad.

Plastics are distributed uniquely. In surface water, the fraction of PP and PE is much larger than in other polymer compositions. The majority of polymers in soil are PA and PP, whereas PP, PE, and PS dominate in sediments (Xu et al., 2020). As a result, the experimental objectives and test purposes could be anticipated based on the density, benefits, and drawbacks of the flotation liquid, and a more suitable flotation solvent could be selected, as shown in Table 1.

Filter membranes are used to filter the supernatant containing MPs generated by density separation. For collection and postidentification, the filter membrane is crucial. The pore size and material requirements of the filter membrane change according to the equipment utilized for MPs' identification. The pore size and substance of the filter membrane should be chosen based on the identification instrument's resolution. A micro-infrared spectrometer, for example, has a spatial resolution of tens of microns, whereas a micro-Raman spectrometer has a spatial resolution of $1 \mu \mathrm{m}$. Glass fiber membranes, cellulose acetate membranes, nitrocellulose membranes, polycarbonate membranes, nylon membranes, metal membranes, and other materials are used to make filter membranes. Glass fiber membranes and polycarbonate membrane ester filter membranes are not suggested. The surface of the glass fiber filter membrane is rough, and fibers may fall out throughout the experiment. Polycarbonate membranes, on the other hand, are not hydrophilic, which makes MP retention difficult. Furthermore, polycarbonate has a strong infrared signal that will interfere with MPs' transmissions. The microplastic signal is present on the nylon membrane itself, interfering with the experiment. The best option is to use metal film. It has a flat surface, no infrared signal, and no micro-plastic signal.

\section{Identification}

After separation, MPs are identified and classified. This mainly involves physical form characterization and chemical component identification, such as size, shape, color, and polymer type. Commonly used techniques include microscopy, spectral analysis, and thermal analysis, etc. (Table 2). 


\section{Physical Form Characterization}

For larger MPs, the characteristics of the physical form can be distinguished with the naked eye within the allowable range of experimental error. For MPs with no specific shape, small size, and light color, a microscope or scanning electron microscope (SEM) can be used to magnify the MPs. Although optical microscopes are simple to operate and can perform routine analysis on samples, they cannot accurately distinguish MPs from other particles (such as natural minerals). Therefore, researchers use the dyeing method to identify MPs. Nile-Red (NR) is a commonly used staining agent, which can specifically bind to neutral lipids, has strong fluorescence in a hydrophobic environment, and is an effective dye for highly hydrophobic MPs. A fluorescence microscope can be used to distinguish particles. This not only reduces the possibility of missing MPs but also reduces the time required to confirm each plastic particle with a spectrometer. Polymers having a particle size of less than $100 \mu \mathrm{m}$ are identified using the NR staining technique. It works well with mixed samples comprising PE, PP, PS, and a lot of inorganic particles. However, because of its low specificity, it will cause other natural compounds to dye colors, such as natural fats in the sample. As a result, this technique is ineffective for identifying MPs in bivalves. The dye was a combination of calcofluor white and Evans's blue 3, and the samples were examined using a laser scanning confocal microscope. The biomass of arthropods is purple, while various polymeric polymers are red, green, and yellow using this approach (Maxwell et al., 2020). Fluorescent counterstaining has been used as a new technology for detecting terrestrial invertebrate biomass and microbes in feces. However, further research is required to determine whether it is suitable for detecting MPs in mollusks tissues. Therefore, it is necessary to select a higher resolution precision instrument for identification, such as SEM.

\section{Chemical Composition Identification}

The spectral analysis technologies commonly used for MPs in mollusks are Raman spectra (Frère et al., 2016) and Fourier transform infrared spectroscopy (FTIR) (Chen et al., 2020). Raman spectra employ laser scattering to identify the polarization of chemical bonds and are mostly used to evaluate materials or chemical compounds that contain aromatic bonds. Although color, fluorescence, additives, and contaminants adsorbed on or imbedded in MPs will impact Raman spectral analysis, the coupling of Raman spectra and microscope technology offers the benefits of employing extremely small sample sizes and spatial resolution (Fu et al., 2020). FTIR is mainly used to analyze polymers with polar functional groups (such as carbonyl). FTIR requires dried samples that must be made into thin films or ground into a powder before analysis. In addition, the premise of obtaining infrared absorption is the change of the dipole moment of the chemical bond. Therefore, to quickly and reliably analyze a large number of optical particles, a combination of Fourier transformed infrared FTIR and Raman microscopy, with a spectral database can determine the particle size, particle size distribution, and polymer types including particle color (Xu et al., 2019; Brandt et al., 2020). This method has been applied to the detection and analysis of mussel MPs
(Vinay Kumar et al., 2021). Further, the chemical components of MPs are also identified by spectral analysis through SEM combined with energy spectrometer technology, and thermal analysis techniques.

Thermo-analytical methods are often considered complementary to spectroscopic methods, such as differential scanning calorimetry, thermogravimetric analysis (TGA) (Zainuddin and Syuhada., 2020), and Pyrolysis gas chromatography-mass spectrometry (Py-GC-MS) (Picó and Damià, 2020), etc. They can identify specific comonomers, additives, and degradation products from plastic fragments (La Nasa et al., 2020). The advantage of Py-GC-MS over conventional spectroscopic methods is that it is possible to analyze polymer types and organic plastic additives in a single analysis. Researchers compared Py-GC-MS, TED-GC-MS, and TGA-FTIR, and found these methods can correctly identify all polymers and report reasonable quantitative results within the study concentration range (Becker et al., 2020). Mass spectrometry analysis requires that polymer samples are purified and concentrated, vaporized, and then entered into mass spectrometry analysis, as vaporization steps, such as laser ablation, may change or destroy the properties of plastic samples.

\section{CHALLENGES AND PROSPECTS}

Since MPs are a relatively new form of environmental contaminant, several scientific issues must be addressed immediately. To begin, consistent and standard detection methods for MPs in various environmental media must be established, as well as qualitative and quantitative detection methods for MPs and their combined contaminants. Various methods for analyzing and identifying MPs are employed, each with its own set of reporting units, resulting in poor comparability of findings. As a result, it's critical to enhance the accuracy, reliability, and comparability of detection data by optimizing qualitative and quantitative analysis methodologies for MPs coupled with contaminants, including standardizing technical procedures and parameters.

Second, image recognition technology has developed since the dawn of the artificial intelligence era. The development of machine vision-based automatic identification, categorization, counting, and measuring procedures for MPs improves data accuracy, lowers labor costs, and saves time. It is anticipated that it will aid in the transformation and advancement of MPs' analysis technology, the types of MPs examined are restricted, and the laboratory circumstances are not representative of actual situations. MPs are often made of fibers and spherical PE, PS, PVC, and other materials, although MPs made of various materials and forms may cause harm to organisms to varying degrees. As a result, future studies must take into account the current environmental circumstances in the area. The absorption and use of MPs by mollusks are influenced by the substance, size, shape, age, and quantity of microplastics. There are limited studies on the mechanisms through which MPs transport contaminants or microbes, as well as long-term dynamic changes and hazards in the maritime environment. 
MPs are presently introduced into the environment at a far quicker rate than they are eliminated. MPs may be found in almost every aquatic habitat on the planet. As a result, several robust environmental protection measures, as well as increased research efforts, are required to curb the rise of microplastics. To begin, additional research into the toxicological impacts of microplastics on filter-feeding mollusks as well as on biological processes should be conducted.

Third, to decrease plastic waste at the source, individuals should reduce their use of plastic items and promote the manufacture and use of degradable plastic products and plastic alternatives. Enhance the usage rate of plastics by recycling and reusing items, and boosting information and scientific research to find microorganisms that can break down microplastics and minimize microplastic pollution.

\section{CONCLUSION}

The most recent research on MPs-mediated contamination in mollusks has been summarized and analyzed, focusing on three main topics: the main methods of MPs separation, extraction, and identification, the current state of shellfish microplastic pollution, and future research hotspots. It suggested that the most common polymer plastics in bivalves are PP, PS, and PE, and the shapes were mainly fiber and threadiness. Mollusks are more likely to feed smaller MPs. Most of the MPs in bivalves are less than $500 \mu \mathrm{m}$. The abundance of MPs in seawater and the abundance of MPs in mollusks have a positive relationship. Additionally, MPs exposure can affect the immune system in mollusks, and the tissue damage, malformations of the nervous system, changes in growth and development, physiological behavior alteration, and adverse effects on the reproduction and heredity in mollusks all mediated by MPs had also been confirmed in the current study. In terms of methodology, $10 \% \mathrm{KOH}$ and $30 \% \mathrm{H}_{2} \mathrm{O}_{2}$ are recommended as the most feasible dissolution methods for studying MPs in mollusks, and the best option for separation is to use metal film. Fluorescent counterstaining has been used as a new technology for detecting terrestrial invertebrate biomass and microbes in feces. It is necessary to select a higher resolution precision instrument for identification, such as SEM. Besides, the future research emphases are also summarized in the present review, including enhancing the accuracy, reliability, and comparability of detection data by optimizing qualitative and quantitative analysis methodologies for MPs, additional

\section{REFERENCES}

Alimi, O. S., Farner Budarz, J., Hernandez, L. M., and Tufenkji, N. (2018). Microplastics and nanoplastics in aquatic environments: aggregation, deposition, and enhanced contaminant transport. Environ. Sci. Technol. 52, 1704-1724. doi: 10.1021/acs.est.7b05559

Andrady, A. L. (2011). Microplastics in the marine environment. Mar. Pollut. Bull. 62, 1596-1605.

Andrady, A. L., and Neal, M. A. (2009). Applications and societal benefits of plastics. Philos. Trans. R. Soc. Lond. B Biol. Sci. 364, 1977-1984.

Antunes, J. C., Frias, J. G. L., Micaelo, A. C., and Sobral, P. (2013). Resin pellets from beaches of the Portuguese coast and adsorbed persistent research into the toxicological impacts of microplastics on filterfeeding mollusks as well as on biological processes should be conducted for environmental protection, and decreasing plastic waste at the source.

\section{AUTHOR CONTRIBUTIONS}

RW and HM: conceptualization. BL: resources. XL and HZ: data curation. RW and HM: writing-original draft preparation. RW and MJ: writing-review and editing. JW: visualization. RW and JW: supervision, project administration, and funding acquisition. All authors have read and agreed to the published version of the manuscript.

\section{FUNDING}

This study was supported financially by grants from the National Natural Science Foundation of China (31902416 and 42077364), Guangdong Province Universities and Colleges Pearl River Scholar Funded Scheme (2018), National Key Research and Development Program of China (2018YFD0900604), and Innovative school strengthening project of Guangdong Provincial Department of Education (2018KTSCX134).

\section{ACKNOWLEDGMENTS}

We appreciate the provision of SCAU Wushan Campus Teaching and Research Base and the Guangzhou JiRui Gene Technology Co., Ltd. for technical support.

\section{SUPPLEMENTARY MATERIAL}

The Supplementary Material for this article can be found online at: https://www.frontiersin.org/articles/10.3389/fmars. 2021.759919/full\#supplementary-material

Supplementary Table 1 | Data about plastic litter found in bivalves.

Supplementary Table 2 | Summary of data found on the literature for MPs and NP uptake, internalization, depuration.

Supplementary Table 3 | Summary of data on uptake, internalization, purification and effects of MPs and other pollutants on bivalves.

organic pollutants. Estuar. Coast Shelf Sci. 130, 62-69. doi: 10.1016/j. ecss

Auta, H. S., Emenike, C. U., and Fauziah, S. H. (2017). Distribution and importance of microplastics in the marine environment: a review of the sources, fate, effects, and potential solutions. Environ. Int. 102, 165-176.

Banerjee, A., and Shelver, W. L. (2021). Micro- and nanoplastic induced cellular toxicity in mammals: a review. Sci Total Environ. 755:142518. doi: 10.1016/j. scitotenv.2020.142518

Becker, R., Altmann, K., Sommerfeld, T., and Braun, U. (2020). Quantification of microplastics in a freshwater suspended organic matter using different thermoanalytical methods-outcome of an interlaboratory comparison. J. Anal. Appl. Pyrol. 148:104829. 
Berglund, E., Fogelberg, V., Nilsson, P. A., and Hollander, J. (2019). Microplastics in a freshwater mussel (Anodonta anatina) in Northern Europe. Sci. Total Environ. 20:134192.

Beyer, J., Green, N. W., Brooks, S., Allan, I. J., Ruus, A., Gomes, T., et al. (2017). Blue mussels (Mytilus edulis spp.) as sentinel organisms in coastal pollution monitoring: a review. Mar. Environ. Res. 130, 338-365.

Birnstiel, S., Soares-Gomes, A., and da Gama, B. (2019). Depuration reduces microplastic content in wild and farmed mussels. Mar. Pollut. Bull. 140, 241247.

Bowley, J., Baker-Austin, C., Porter, A., Hartnell, R., and Lewis, C. (2021). Oceanic hitchhikers-assessing pathogen risks from marine microplastic. Trends Microbiol. 29, 107-116.

Brandt, J., Bittrich, L., Fischer, F., Kanaki, E., Tagg, A., Lenz, R., et al. (2020). High-throughput analyses of microplastic samples using fourier transform infrared and raman spectrometry. Appl. Spectrosc. 74, 1185-1197. doi: 10.1177/ 0003702820932926

Bringer, A., Cachot, J., Prunier, G., Dubillot, E., Clérandeau, C., and Thomas, H. (2020a). Experimental ingestion of fluorescent microplastics by pacific oysters, Crassostrea gigas, and their effects on the behaviour and development at early stages. Chemosphere (Oxford). 254:126793.

Bringer, A., Thomas, H., Prunier, G., Dubillot, E., Bossut, N., Churlaud, C., et al. (2020b). High density polyethylene (HDPE) microplastics impair development and swimming activity of Pacific oyster D-larvae, Crassostrea gigas, depending on particle size. Environ. Pollut. 260:113978. doi: 10.1016/j.envpol.2020. 113978

Browne, M. A., Crump, P., Niven, S. J., Teuten, E., Tonkin, A., Galloway, T., et al. (2011). Accumulation of microplastic on shorelines woldwide: sources and sinks. Environ. Sci. Technol. 45, 9175-9179. doi: 10.1021/es201811s

Browne, M. A., Dissanayake, A., Galloway, T. S., Lowe, D. M., and Thompson, R. C. (2008). Ingested microscopic plastic translocates to the circulatory system of the mussel. Mytilus edulis (L). Environ. Sci. Technol. 42, 5026-5031. doi: 10.1021/es800249a

Canesi, L., Ciacci, C., Bergami, E., Monopoli, M. P., Dawson, K. A., Papa, S., et al. (2015). Evidence for immunomodulation and apoptotic processes induced by cationic polystyrene nanoparticles in the hemocytes of the marine bivalve Mytilus. Mar. Environ. Res. 111, 34-40.

Catarino, A. I., Thompson, R., Sanderson, W., and Henry, T. B. (2017). Development and optimization of a standard method for extraction of microplastics in mussels by enzyme digestion of soft tissues. Environ. Toxicol. Chem. 36, 947-951. doi: 10.1002/etc.3608

Chen, Q., Reisser, J., Cunsolo, S., Kwadijk, C., Kotterman, M., Proietti, M., et al. (2018). Pollutants in plastics within the North Pacific subtropical gyre. Environ. Sci. Technol. 52, 446-456. doi: 10.1021/acs.est.7b04682

Chen, Y., Wen, D., Pei, J., Fei, Y., Ouyang, D., Zhang, H., et al. (2020). Identification and quantification of microplastics using Fourier-transform infrared spectroscopy: current status and future prospects. Curr. Opin. Environ. Health 18, 14-19. doi: 10.1016/j.coesh.2020.05.004

Claessens, M., Van Cauwenberghe, L., Vandegehuchte, M. B., and Janssen, C. R. (2013). New techniques for the detection of microplastics in sediments and field collected organisms. Mar. Pollut. Bull. 70, 227-233. doi: 10.1016/j.marpolbul 2013.03.009

Cole, M., Liddle, C., Consolandi, G., Drago, C., Hird, C., Lindeque, P. K., et al. (2020). Microplastics, microfibers and nanoplastics cause variable sub-lethal responses in mussels (Mytilus spp.). Mar. Pollut. Bull. 160:111552.

Cole, M., Lindeque, P., Halsband, C., and Galloway, T. S. (2011). Microplastics as contaminants in the marine environment: a review. Mar. Pollut. Bull. 62, 2588-2597.

Corami, F., Rosso, B., Roman, M., Picone, M., Gambaro, A., and Barbante, C. (2020). Evidence of small microplastics $(<100 \mu \mathrm{m})$ ingestion by Pacific oysters (Crassostrea gigas): a novel method of extraction, purification, and analysis using Micro-FTIR. Mar. Pollut. Bull. 160:111606.

David, K. A. B., Galgani, F., Thompson, R. C., and Barlaz, M. (2009). Accumulation and fragmentation of plastic debris in global environments. Philos. Trans. R. Soc. Lond. B Biol. Sci. 364, 1985-1998.

Desforges, J. P., Galbraith, M., Dangerfield, N., and Ross, P. S. (2014). Widespread distribution of microplastics in subsurface seawater in the NE Pacific Ocean. Mar. Pollut. Bull. 79, 94-99.
Ding, J., Li, J., Sun, C., He, C., Jiang, F., Gao, F., et al. (2018). Separation and identification of microplastics in digestive system of bivalves. Chinese J. Anal. Chem. 46, 690-697. doi: 10.1016/s1872-2040(18)61086-2

Eriksen, M., Lebreton, L. C., Carson, H. S., Thiel, M., Moore, C. J., Borerro, J. C., et al. (2014). Plastic pollution in the world's oceans: more than 5 trillion plastic pieces weighing over 250,000 tons afloat at sea. PLoS One 9:e111913. doi: 10.1371/journal.pone.0111913

Fackelmann, G., and Sommer, S. (2019). Microplastics and the gut microbiome: how chronically exposed species may suffer from gut dysbiosis. Mar. Pollut. Bull. 143, 193-203. doi: 10.1016/j.marpolbul.2019. 04.030

Farrell, P., and Nelson, K. (2013). Trophic level transfer of microplastic: Mytilus edulis (L.) to Carcinus maenas (L.). Environ. Pollut. 177, 1-3. doi: 10.1016/j. envpol.2013.01.046

Fendall, L. S., and Sewell, M. A. (2009). Contributing to marine pollution by washing your face: microplastics in facial cleansers. Mar. Pollut. Bull. 58, 1225-1228. doi: 10.1016/j.marpolbul.2009.04.025

Fernández, B., and Albentosa, M. (2019a). Dynamic of small polyethylene microplastics $(=10 \mu \mathrm{m})$ in mussel's tissues. Mar. Pollut. Bull. 146, 493-501. doi: 10.1016/j.marpolbul.2019.06.021

Fernández, B., and Albentosa, M. (2019b). Insights into the uptake, elimination and accumulation of microplastics in mussel. Environ. Pollut. 249, 321-329. doi: 10.1016/j.envpol.2019.03.037

Frère, L., Maignien, L., Chalopin, M., Huvet, A., Rinnert, E., Morrison, H., et al. (2018). Microplastic bacterial communities in the Bay of Brest: influence of polymer type and size. Environ. Pollut. 242(Pt A), 614-625. doi: 10.1016/j. envpol.2018.07.023

Frère, L., Paul-Pont, I., Moreau, J., Soudant, P., Lambert, C., Huvet, A., et al. (2016). A semi-automated Raman micro-spectroscopy method for morphological and chemical characterizations of microplastic litter. Mar. Pollut. Bull. 113, 461-468. doi: 10.1016/j.marpolbul.2016.10.051

Fries, E., Dekiff, J. H., Willmeyer, J., Nuelle, M. T., Ebert, M., and Remy, D. (2013). Identification of polymer types and additives in marine microplastic particles using pyrolysis-GC/MS and scanning electron microscopy. Environ. Sci. Process Impacts. 15, 1949-1956. doi: 10.1039/c3em00214d

Fu, W., Min, J., Jiang, W., Li, Y., and Zhang, W. (2020). Separation, characterization and identification of microplastics and nanoplastics in the environment. Sci. Total Environ. 721:137561. doi: 10.1016/j.scitotenv.2020. 137561

Galvão, A., Aleixo, M., De Pablo, H., Lopes, C., and Raimundo, J. (2020). Microplastics in wastewater: microfiber emissions from common household laundry. Environ. Sci. Pollut. Res. Int. 27, 26643-26649. doi: 10.1007/s11356020-08765-6

Glenny, E. M., Bulik-Sullivan, E. C., Tang, Q., Bulik, C. M., and Carroll, I. M. (2017). Eating disorders and the intestinal microbiota: mechanisms of energy homeostasis and behavioral influence. Curr. Psychiatry Rep. 19:51. doi: 10.1007/ s11920-017-0797-3

Gniadek, M., and Dąbrowska, A. (2019). The marine nano- and microplastics characterisation by SEM-EDX: the potential of the method in comparison with various physical and chemical approaches. Mar. Pollut. Bull. 148, 210-216. doi: 10.1016/j.marpolbul.2019.07.067

González-Fernández, C., Tallec, K., Le Goïc, N., Lambert, C., Soudant, P., Huvet, A., et al. (2018). Cellular responses of Pacific oyster (Crassostrea gigas) gametes exposed in vitro to polystyrene nanoparticles. Chemosphere 208, 764-772. doi: 10.1016/j.chemosphere.2018.06.039

Graham, P., Palazzo, L., Andrea de Lucia, G., Telfer, T. C., Baroli, M., and Carboni, S. (2019). Microplastics uptake and egestion dynamics in Pacific oysters, Magallana gigas (Thunberg, 1793), under controlled conditions. Environ. Pollut. 252(Pt A), 742-748. doi: 10.1016/j.envpol.2019. 06.002

Green, D. S., Colgan, T. J., Thompson, R. C., and Carolan, J. C. (2019). Exposure to microplastics reduces attachment strength and alters the haemolymph proteome of blue mussels (Mytilus edulis). Environ. Pollut. 246, 423-434. doi: 10.1016/j.envpol.2018.12.017

Huppertsberg, S., and Knepper, T. P. (2018). Instrumental analysis of microplastics-benefits and challenges. Anal. Bioanal. Chem. 410, 6343-6352. doi: $10.1007 /$ s00216-018-1210-8 
Hurley, R. R., Lusher, A. L., Olsen, M., and Nizzetto, L. (2018). Validation of a method for extracting microplastics from complex, organic-rich, environmental matrices. Environ. Sci. Technol. 52, 7409-7417. doi: 10.1021/acs. est.8b01517

Jin, Y., Xia, J., Pan, Z., Yang, J., Wang, W., and Fu, Z. (2018). Polystyrene microplastics induce microbiota dysbiosis and inflammation in the gut of adult zebrafish. Environ. Pollut. 235, 322-329. doi: 10.1016/j.envpol.2017. 12.088

Junaid, M., and Wang, J. (2021). Interaction of nanoplastics with extracellular polymeric substances (EPS) in the aquatic environment: a special reference to eco-corona formation and associated impacts. Water Res. 201, 117319. doi: 10.1016/j.watres.2021.117319

Ke, A., Chen, J., Zhu, J., Wang, Y., Hu, Y., Fan, Z., et al. (2019). Impacts of leachates from single-use polyethylene plastic bags on the early development of clam Meretrix meretrix (Bivalvia: Veneridae). Mar. Pollut. Bull. 142, 54-57. doi: 10.1016/j.marpolbul.2019.03.029

Kesy, K., Oberbeckmann, S., Müller, F., and Labrenz, M. (2016). Polystyrene influences bacterial assemblages in Arenicola marina-populated aquatic environments in vitro. Environ Pollut. 219, 219-227. doi: 10.1016/j.envpol.2016. 10.032

Kolandhasamy, P., Su, L., Li, J., Qu, X., Jabeen, K., and Shi, H. (2018). Adherence of microplastics to soft tissue of mussels: a novel way to uptake microplastics beyond ingestion. Sci. Total Environ. 61, 635-640. doi: 10.1016/j.scitotenv.2017. 08.053

La Nasa, J., Biale, G., Fabbri, D., and Modugno, F. (2020). A review on challenges and developments of analytical pyrolysis and other thermoanalytical techniques for the quali-quantitative determination of microplastics. J. Anal. Appl. Pyrol. 149:104841. doi: 10.1016/j.jaap.2020. 104841

Li, L., Li, M., Deng, H., Cai, L., Cai, H., Yan, B., et al. (2018). A straightforward method for measuring the range of apparent density of microplastics. Sci. Total Environ. 639, 367-373. doi: 10.1016/j.scitotenv.2018. 05.166

Li, L., Su, L., Cai, H., Rochman, C. M., Li, Q., Kolandhasamy, P., et al. (2019a). The uptake of microfibers by freshwater Asian clams (Corbicula fluminea) varies based upon physicochemical properties. Chemosphere 221, 107-114. doi: 10.1016/j.chemosphere.2019.01.024

Li, L., Zhu, J., Li, J., Cai, H., and Shi, H. (2019b). Review on methods for extraction and isolation of microplastics in aquatic organisms. J. Oceanol. Environ. Sci. China 38:197. doi: 10.13634/j.cnki.mes.2019. 02.004

Liu, Y., Li, R., Yu, J., Ni, F., Sheng, Y., Scircle, A., et al. (2020). Separation and identification of microplastics in marine organisms by TGA-FTIR-GC/MS: a case study of mussels from coastal China. Environ. Pollut. 272:115946. doi: 10.1016/j.envpol.2020.115946

Llorca, M., Vega-Herrera, A., Schirinzi, G., Savva, K., Abad, E., and Farre, M. (2021). Screening of suspected micro(nano)plastics in the Ebro Delta (Mediterranean Sea). J. Hazard Mater. 404:124022. doi: 10.1016/j.jhazmat.2020. 124022

Maxwell, S. H., Melinda, K. F., and Matthew, G. (2020). Counterstaining to separate nile red-stained microplastic particles from terrestrial invertebrate biomass. Environ. Sci. Technol. 54, 5580-5588. doi: 10.1021/acs.est.0c0 0711

Moore, C. J. (2008). Synthetic polymers in the marine environment: a rapidly increasing, long-term threat. Environ. Res. 108, 131-139. doi: 10.1016/j.envres. 2008.07.025

Patel, M. M., Goyal, B. R., Bhadada, S. V., Bhatt, J. S., and Amin, A. F. (2009). Getting into the brain: approaches to enhance brain drug delivery. CNS Drugs 23, 35-58. doi: 10.2165/0023210-20092301000003

Pedersen, A. F., Gopalakrishnan, K., Boegehold, A. G., Peraino, N. J., Westrick, J. A., and Kashian, D. R. (2020). Microplastic ingestion by quagga mussels, Dreissena bugensis, and its effects on physiological processes. Environ. Pollut. 260:113964. doi: 10.1016/j.envpol.2020.113964

Picó, Y., and Damià, B. (2020). Pyrolysis gas chromatography-mass spectrometry in environmental analysis: focus on organic matter and microplastics. $\operatorname{Tr} A C$ Trends Anal. Chem. 130:115964. doi: 10.1016/j.trac.2020.115964
Prata, J. C., da Costa, J. P., Lopes, I., Duarte, A. C., and Rocha-Santos, T. (2020). Environmental exposure to microplastics: an overview on possible human health effects. Sci. Total Environ. 702:134455. doi: 10.1016/j.scitotenv.2019. 134455

Qu, X., Su, L., Li, H., Liang, M., and Shi, H. (2018). Assessing the relationship between the abundance and properties of microplastics in water and in mussels. Sci. Total Environ. 621, 679-686. doi: 10.1016/j.scitotenv.2017.11.28

Rani, M., Shim, W. J., Jang, M., Han, G. M., and Hong, S. H. (2017). Releasing of hexabromocyclododecanes from expanded polystyrenes in seawater field and laboratory experiments. Chemosphere 185, 798-805. doi: 10.1016/j. chemosphere.2017.07.042

Scanes, E., Wood, H., and Ross, P. (2019). Microplastics detected in haemolymph of the Sydney rock oyster Saccostrea glomerata. Mar. Pollut. Bull. 149:110537. doi: 10.1016/j.marpolbul.2019.110537

Silva, A. B., Bastos, A. S., Justino, C., da Costa, J. P., Duarte, A. C., and RochaSantos, T. (2018). Microplastics in the environment: challenges in analytical chemistry-A review. Anal. Chim. Acta 1017, 1-19. doi: 10.1016/j.aca.2018.02. 043

Song, J. A., Choi, C. Y., and Park, H. (2020). Exposure of bay scallop Argopecten irradians to micro-polystyrene: bioaccumulation and toxicity. Comp Biochem Phy \& C. 236:108801. doi: 10.1016/j.cbpc.2020.108801

Suaria, G., and Aliani, S. (2014). Floating debris in the Mediterranean Sea. Mar. Pollut. Bull. 86, 494-504. doi: 10.1016/j.marpolbul.2014.06.025

Tang, G., Liu, M., Zhou, Q., He, H., Chen, K., Zhang, H., et al. (2018). Microplastics and polycyclic aromatic hydrocarbons (PAHs) in Xiamen coastal areas: implications for anthropogenic impacts. Sci. Total Environ. 634, 811-820. doi: 10.1016/j.scitotenv.2018.03.336

Thiele, C. J., Hudson, M. D., and Russell, A. E. (2019). Evaluation of existing methods to extract microplastics from bivalve tissue: adapted $\mathrm{KOH}$ digestion protocol improves filtration at single-digit pore size. Mar. Pollut. Bull. 142, 384-393. doi: 10.1016/j.marpolbul.2019.03.003

Van Cauwenberghe, L., and Janssen, C. R. (2014). Microplastics in bivalves cultured for human consumption. Environ. Pollut. 193, 65-70. doi: 10.1016/j.envpol. 2014.06.010

Van Emmerik, T., Strady, E., Kieu-Le, T. C., Nguyen, L., and Gratiot, N. (2019). Seasonality of riverine macroplastic transport. Sci. Rep. 9:13549. doi: 10.1038/ s41598-019-50096-1

Vinay Kumar, B. N., Löschel, L. A., Imhof, H. K., Löder, M., and Laforsch, C. (2021). Analysis of microplastics of a broad size range in commercially important mussels by combining FTIR and Raman spectroscopy approaches. Environ. Pollut. 269:116147. doi: 10.1016/j.envpol.2020.116147

Von Friesen, L. W., Granberg, M. E., Hassellöv, M., Gabrielsen, G. W., and Magnusson, K. (2019). An efficient and gentle enzymatic digestion protocol for the extraction of microplastics from bivalve tissue. Mar. Pollut. Bull. 142, 129-134. doi: 10.1016/j.marpolbul.2019.03.016

Wang, X., Zhu, Q., Yan, X., Wang, Y., Liao, C., and Jiang, G. (2020). A review of organophosphate flame retardants and plasticizers in the environment: analysis, occurrence and risk assessment. Sci. Total Environ. 731:139071. doi: 10.1016/j. scitotenv.2020.139071

Wesch, C., Bredimus, K., Paulus, M., and Klein, R. (2016). Towards the suitable monitoring of ingestion of microplastics by marine biota: a review. Environ. Pollut. 218, 1200-1208. doi: 10.1016/j.envpol.2016. 08.076

Wright, S. L., Thompson, R. C., and Galloway, T. S. (2013). The physical impacts of microplastics on marine organisms: a review. Environ. Pollut. 178, 483-492. doi: 10.1016/j.envpol.2013.02.031

Wu, B., Wu, X., Liu, S., Wang, Z., and Chen, L. (2019). Size-dependent effects of polystyrene microplastics on cytotoxicity and efflux pump inhibition in human Caco-2 cells. Chemosphere (Oxford). 221, 333-341. doi: 10.1016/j.chemosphere. 2019.01.056

Xia, W., Rao, Q., Deng, X., Chen, J., and Xie, P. (2020). Rainfall is a significant environmental factor of microplastic pollution in inland waters. Sci. Total Environ. 732:139065. doi: 10.1016/j.scitotenv.2020.139065

Xu, C., Zhang, B., Gu, C., Shen, C., Yin, S., Aamir, M., et al. (2020). Are we underestimating the sources of microplastic pollution in terrestrial environment? J. Hazard Mater. 400:123228. doi: 10.1016/j.jhazmat.2020. 123228 
Xu, J., Thomas, K. V., Luo, Z., and Gowen, A. A. (2019). FTIR and raman imaging for microplastics analysis: state of the art, challenges and prospects. TrAC Trend Anal. Chem. 119:115629. doi: 10.1016/j.trac.2019.115629

Xu, X. Y., Lee, W. T., Chan, A., Lo, H. S., Shin, P., and Cheung, S. G. (2017). Microplastic ingestion reduces energy intake in the clam Atactodea striata. Mar. Pollut. Bull. 124, 798-802. doi: 10.1016/j.marpolbul.2016.12.027

Zainuddin, Z., and Syuhada. (2020). Study of analysis method on microplastic identification in bottled drinking water. Macromol. Symp. 391:1900195. doi: 10.1002/masy.201900195

Zhang, X., Yan, B., and Wang, X. (2020a). Selection and optimization of a protocol for extraction of microplastics from Mactra veneriformis. Sci. Total Environ. 746:141250. doi: 10.1016/j.scitotenv.2020.141250

Zhang, X., Yu, K., Zhang, H., Liu, Y., He, J., Liu, X., et al. (2020b). A novel heatingassisted density separation method for extracting microplastics from sediments. Chemosphere 256:127039. doi: 10.1016/j.chemosphere.2020.127039

Zhu, X., Qiang, L., Shi, H., and Cheng, J. (2020). Bioaccumulation of microplastics and its in vivo interactions with trace metals in edible oysters. Mar. Pollut. Bull. 154:111079. doi: 10.1016/j.marpolbul.2020.111079

Zimmermann, L., Dierkes, G., Ternes, T. A., Völker, C., and Wagner, M. (2019). Benchmarking the in vitro toxicity and chemical composition of plastic consumer products. Environ. Sci. Technol. 53, 11467-11477. doi: 10.1021/acs. est.9b022

Conflict of Interest: The authors declare that the research was conducted in the absence of any commercial or financial relationships that could be construed as a potential conflict of interest.

Publisher's Note: All claims expressed in this article are solely those of the authors and do not necessarily represent those of their affiliated organizations, or those of the publisher, the editors and the reviewers. Any product that may be evaluated in this article, or claim that may be made by its manufacturer, is not guaranteed or endorsed by the publisher.

Copyright (c) 2021 Wang, Mou, Lin, Zhu, Li, Wang, Junaid and Wang. This is an open-access article distributed under the terms of the Creative Commons Attribution License (CC BY). The use, distribution or reproduction in other forums is permitted, provided the original author(s) and the copyright owner(s) are credited and that the original publication in this journal is cited, in accordance with accepted academic practice. No use, distribution or reproduction is permitted which does not comply with these terms. 